\title{
Direct Method for teaching Arabic language in Tongxin Arabic college of Ningxia in China
}

\author{
Ma Xuan \\ Sultan Idris education university Malaysia \\ Suo Yan Mei \\ Sultan Idris Education University Malaysia
}

\begin{abstract}
It is known that teaching methods are very important in the teaching foreign languages. This research aims to explain the direct teaching method for Arabic language in Tongxin Ningxia in China, and how to implement it and the problems encountered by the Arabic teachers during the teaching. The researcher used the inductive method to explore various ways of teaching Arabic language and adopted the historical approach to uncover the historical development and development of this college, as well as teaching the Arabic language in it. And the field approach to highlight the problems faced by teachers of Arabic language and students in the teaching and study of Arabic language at the Faculty of Arabic Language in Tongxin on the method of observations and interview. The researchers also used the descriptive approach in the collection of information related to it, as well as the analytical approach to obtain the results of the effectiveness of direct teaching methods using by questionnaire. The researcher selected 100 students and 10 teachers from this college. The data were analyzed using spss program. And Statistical processing was performed using the frequency distribution and percentage. The results of the research show that even though methods of teaching Arabic are multiple, there is no typical way in teaching, each method has its own advantages and disadvantages. But according the result, the majorly of students and teachers found that direct teaching method is highly encourage to be implement during Arabic class.
\end{abstract}

Keyword: Direct method, Teaching, Arabic language.

\section{Introduction}

The teaching methods of foreign languages are famous and widespread in the world, especially for English. As for the teaching of the Arabic language, has many ways, there are many researchers have written researches related to this topic to benefit for teaching of Arabic, but the fact that the teaching methods of the Arabic language is different from other foreign languages relatively, and this is due to the characteristics of Arabic language and its advantages, Arabic is a rich and fairly accurate language.

The direct method of teaching one of the foreign languages, as described by Rushdie Ahmed Taima (1986) as characterized by four entrances, the most important points are: Distinguish them in natural order in learning language skills that begin with listening, speaking, reading, writing, since the individual writes only what Read, and read only what he uttered, and speaks only what he listened to. In short, the direct method is compatible with the learning of the mother tongue.

The researchers believe that the direct method is the best way for the students who are non- native speakers. The teacher did not seem to think very well, and as the designer, the lessons should prepare all the readiness to benefit the students from teaching which they like the material they teach. But there are a lot of teachers and lecturers know what they teach, but they do not know how to teach. Therefore, we need to discuss this topic. Hence this research helps teachers of Arabic to know the direct method and how to use it, especially for teaching Arabic speakers.

One of the researchers taught Arabic for Chinese students at the Tongxin Arabic Language College ten years ago. Through this long period, we noticed that the students are weak in the four basic Arabic language skills: listening, speaking, reading 
and writing. This is because of lack of efforts and lack of information, therefore the teachers implement the single teaching methods alone, seldom use the direct method during their teaching Arabic language. The researchers realized the importance of the direct method in teaching Arabic language, especially for students who are non- native speakers

This study focus on clarifying the purpose of the direct method, its importance and its advantages in the teaching Arabic language by using it for students who are non- native speakers and tried to solve the problems in the Arabic language college of Tongxin.

\section{The statement of Problem}

There are many problems in applying the direct method to teaching Arabic language for most teachers and students in the tongxin Arabic Language College in China. Those problems makes researchers to study this topic. Those problems are: Lack of good knowledge of the direct method and lack of implement this method in the teaching Arabic language; most of them apply single method often during the lectures, namely the method of translation and grammar; the lack of appropriate teaching method for the direct method of teaching Arabic language at the Tongxin Arabic Language college .And the students are very week in speaking and listening even thought they had learned Arabic language for long time already ,all problems which mentioned above lead to difficulties in the application of the direct method.

\section{Objectives of the research}

The study aims to achieve the following objectives:

1- To Simplify knowledge for the direct method of teaching Arabic language.

2- To explain the importance of the direct method in teaching Arabic for non- native speakers.

3- To demonstrate the advantages and disadvantages of the direct method in language teaching.

4-To evaluate the effectiveness of the direct method and problems of application in the teaching of Arabic language at the Tongxin Arabic Language College.

\section{The importance of research}

The importance of this study is divided into a theoretical and an applied point of view, and in theory it is the identification of the direct method of teaching Arabic language to non-Arabic speakers, their importance, their advantages and disadvantages and the understanding of the direct method and how to use it in teaching.

On the practical side, this study is a way to solve the problems faced by teachers of Arabic language for non- native speakers, and encourage them to implement the direct method of teaching to improve their level of education and the ability of students to speak proficiency at the Faculty of Arabic Tongxin.

\section{Research method}

This research relies on the inductive method to collect data and information related to direct methods, their origin and characteristics, as well as the information related to the backgrounds of the Tongxin Arabic Language College, its origin and the level of teachers of Arabic language. The researcher is based on the observation of the problem of application of the direct method in teaching Arabic language. The researcher selected 100 students and 11 teachers from this college. The researcher is based on the observation of the observation to the practical problems of the direct method of teaching Arabic language. The researcher collects the information related to the interview of the teachers and students at the Arabic language school in Tongxin.

Besides that, the research dopants on the descriptive approach to a deep study of the direct method, describing it exactly in terms of definitions and characteristics, and clarifying practical obstacles and difficulties in its teaching through analyzing previous studies and collecting information and references.

It also depends on the analytical method of resurrection by collecting all the questionnaire by answering Arabic and Arabic language teachers in Tongxin and analyzing the questionnaires to solve the problems related to the direct method.

In order to obtain effectively information, the researchers choose the sample in a simple random way. The total number of Arabic language teachers who teach at the Tongxin Arabic Language College is 10 teachers, including 8 teachers who 
received a bachelor's degree and two teachers with a master's degree. The sample size of the students is 100 students. The researchers also randomly choose 50 students in the second year and 50 students in the third year .And the statistical analysis program SPSS is to conduct the numerical analysis, graphs, tables and percentage, and then the researchers present the findings. And analyze to extract evidence and facts.

\section{Analysis of questionnaires}

The purpose of this research is to examine the problems presented in the application of the direct method of teaching Arabic in the Faculty of Arabic Language in Tongxin. In order to achieve this goal, the researcher conducted the questionnaire on the sample members of the teachers of Arabic language and students in this college.

The sample population of the teachers consists of 11 teachers who teach the Arabic language, and their students who study in this school from different classes in three stages: the first, second and third year. The researcher chose these students for different information.

The number of questionnaires distributed to the students in this college was one hundred (100), ie 30 for the first year, 40 for the second year and 30 for the third year. The response rate was $100 \%$ for students and $100 \%$ for teachers.

\section{Analysis of teachers' questionnaire}

The questionnaires distributed to these teachers included twenty questions related to the different issues that we can identify as follows: 1) Six questions in the first section aimed at obtaining general information about the teachers' personalities; 2) Eleven of them in the second part of closed questions Which relate to their views on the practical problems of the direct method of teaching Arabic; 3) Three questions, including the third section of the open questions on how to solve these problems.

Through the analysis, the researcher obtained the following valuable information:

\section{General Information:}

The ratio of teachers and teachers in the college is not equal first. This indicates that most of the teachers in the college have a beautiful patience in teaching the Arabic language, which requires patience more than other materials. Therefore, the educational qualifications of the teachers in this college are high and reasonable. Because most of them have a bachelor's or master's degree, accounting for $73 \% ; 64 \%$ of the teachers have more than five years of experience in education, and most of the teachers in the college do not care about their individual development, because $56 \%$ of teachers do not participate In training courses always, or never participate in. While most teachers are busy in education, they do not have enough times to study general teaching methods and to study the direct method of the particular.

\section{Closed questions}

The answer to opinions about the direct method, etc., is required to determine the extent of approval. The result of the answers is summarized as follows:

All teachers know about the direct method almost, their proportion has reached about $91 \%$. But the number of teachers who use the direct method in teaching Arabic for beginners 8 teachers, has reached about $74 \%$, and this indicates that the extent of application of this method in the college is relatively large, but limited to the primary stage only.

- $65 \%$ of teachers see that their students are not excellent in the skill of speech, this means that the ability of students in the skill of speech need to upgrade and development is an urgent need for them.

- Most teachers see that the main problem faced by students in speaking Arabic is the lack of the appropriate study environment, and $55 \%$ of them admit that individual teaching methods. Also of the problem is the task. $65 \%$ of teachers often rely on the method of translation and grammar in teaching Arabic.

- $65 \%$ of teachers believe that the direct method does not take into account individual differences among students.

- Most teachers confirm that students do not have a strong desire to learn Arabic, which leads to weakness in the skills of four, where the number reached eight, representing $73 \%$. 
- Nine teachers agree that the specialized books, especially the direct way incomplete in the college, and the proportion of $82 \%$. Perhaps this is an original reason for the weakness of knowledge in this way and mastery of the college teachers.

- Seven teachers in the approval of the direct method does not suit all the materials of the Arabic language, and their proportion is $64 \%$. Perhaps this is one of the disadvantages of the direct method.

As for the view of "the practical problems of the direct method in the Tongxin Arabic Language School is the teacher's lack of interest in using them." Most of the teachers do not agree with this view, and they numbered six person where he got about $55 \%$.

\section{Open Questions}

1- The direct method is the best way to increase the speech skills of other speakers. What do you think of this talk?

From the teachers' answers, we learned that eight teachers fully agree with this view. Their argument: The direct method urges them to speak and express more. And three teachers do not agree, one believes that the direct method is useful and effective in education without doubt. In this way students can get used to the linguistic environment and listen and speak until they think the target language from the beginning of studies, so they can understand and raise their level of expression. But on the other hand does not see the researcher that this method is appropriate for each professor or student because this method neglects to help the mother tongue, if there is some difficult information in education, it is easy to occur this misunderstanding and waste time also. The other said: This method helps students to strengthen their ability to speak and verbal expression on the one hand and on the other hand it also benefits students in their ability to listen. But this method is not suitable for teaching all materials for the Arabic language.

The third is that the direct method is very suitable for beginners and not suitable for students in the second and third year, teachers must be associated with other methods in the teaching of Arabic speakers.

\section{2- What are the practical problems of the direct method in the Tongxin Arabic Language School?}

The researcher summarizes the teachers' answers as follows:

Teachers use the traditional method of teaching Arabic, which is fundamentally dependent on grammar, not on everyday language practice and is committed to translation methods, so they may not have time to speak Arabic in and out of the classroom.

Teachers cannot use Arabic at all times because they are limited. The ability of students to understand Arabic is weak if they learn the direct method without the help of the mother tongue.

Non-application of the direct method in some professors. Because of the lack of linguistic environment and lack of cooperation and response between students and professors, because students in our college are still young in their age and are weak in Chinese language also makes them do not understand what the professor taught.

The application of the direct method requires teachers to have abundant experience, and the professor with abundant experience can make the lesson atmosphere active and therefore students want to express without fear and concern.

Most teachers do not know how to apply the direct method well and not understand the direct method of understanding correctly at the professors. Many of the Arabic language teachers do not have references to modern teaching methods, especially the direct method.

Students lack the desire to study and are not determined to study.

3 - What are the ways to solve the practical problems of the direct method?

The researcher summarizes the views of teachers in this regard as follows:

Teachers should speak Arabic while teaching and their students should speak Arabic from the beginning of the study even in a few words and in simplified terms. However, teachers should encourage their students to speak the simplest sentences or words in Arabic and to participate in language activities, especially in Arabic. 
Teachers should reduce the explanation of grammar in the mother tongue and interest in translation when the lesson. They do not correct their mistakes, even though they exist.

Teachers must first study this method so that they know what they mean.

The college should encourage teachers to use the direct method during teaching.

Creating the linguistic environment inside and outside the college between the teachers first and then the students and inventing the corner of the Arabic language once a week.

The faculty must be equipped with various tools for use by teachers in the direct way.

\section{Analysis of students' questionnaire}

This section deals with the analysis of students' questionnaire on the application of teachers to the direct method in this college. Which:

What is a common method used by teachers to teach?

The method of grammar and translation in the teaching of faculty members from the perspective of students is a common method where he got $70 \%$ followed by the direct method and $14 \%$, then the method of reading, which is $9 \%$, and then the method of communication and the proportion of $5 \%$, while the audiovisual method, $\%$ Just. In general, we note that direct method is not a common method in college.

Which way would you benefit the most?

Shows that the method that benefits the students more is the method of grammar and translation where he got $52 \%$, followed by the direct method, $20 \%$ of students benefit from this method, then the audiovisual method was $13 \%$, and the method of reading is only $8 \%$.

What methods does the professor use to explain new words and difficult phrases?

$47 \%$ of the students say that the teachers use the reference to explain the new words and difficult phrases, followed by the representation where he got $28 \%$, and the fees considered by the third rank was up to $20 \%$. The least chosen method is the sound, which is only $5 \%$. This shows that teachers have a variety, most of them reference. However, both representation and graphics play an important role in direct method use, and sound as well. The song was a favorite way of teaching the language, but it seems that it was not used by professors at the college.

Any material taught by the professor in the direct way?

The answer is that the material used by the teachers is the direct method of the first level is the conversation where he received $69 \%$, while the second place was followed by $12 \%$, followed by reading and construction, each ranked third, or $8 \%$. The rules use this method in which the lowest ratio is only $3 \%$. Therefore we note that the direct method used in this college is not available.

What language activities do students prefer?

The language activities designed to be preferred by the students in this college are watching Arabic films where $40 \%$ have been obtained. This will benefit the application of the direct method. Thus, speaking Arabic in the classroom or outside it is the second rank of the preferred activities, and amounted to $31 \%$, and then summarize the text before the pupils, the proportion of this activity $24 \%$, while reading the Koran

Each day he won the last rank and their proportion of only $5 \%$. This is very small for those who study the language of the Qur'an, because it is known that the Arabic language is the language of the Qur'an itself, so we do not neglect it in teaching.

What activity does the teacher do while teaching?

The questionnaire shows that $3 \%$ of the students believe that the activity of the teacher during the teaching is linguistic puzzles, and $7 \%$ of the students see him as a match between the students. Many of them say that the activity is Arab 
rhetoric, where it got $38 \%$. And $6 \%$ of them consider the Arabic song, and most students believe that the reading contest is the activity taken during teaching.

If the professor used the direct method length of the quota, can you accept this method?

The questionnaire shows that only a small number of students wish to do so. Their percentage is only $15 \%$. This indicates that these students are strong in listening and speaking skills, as well as their high capacity on both sides. $21 \%$ of the students are accepted, $18 \%$ do not accept at all, while the percentage of others who accept them has the highest percentage of $46 \%$. However, the condition is that the professor needs to explain some words in Chinese. This tells us that they are weak in listening and speaking and are dependent on the mother tongue.

How to answer the questions posed by the professor in Arabic?

The questionnaire shows that few students answer the questions directly in Arabic, where they received $14 \%$. Most of the students cannot answer the questions directly, but they think about their objectives first and then answer them in Arabic, $79 \%$, while $9 \%$ of the students understand the purpose of the questions. But they cannot answer in Arabic, and weaker than that there are some students see that they do not understand the intent of the questions and does not answer them. From this conclusion, the researcher sees that the development of the linguistic idea is very important, so it needs to use the direct method of urgent need.

How do you usually save new words?

The result of the questionnaire explained that the methods of memorizing the new words among the students are varied. $31 \%$ of the students take the method of reading the word in high volume several times in order to memorize it. Many of them memorize the short sentence in which the required word is given. $36 \%$ of them are speaking with their friends. And the remaining students read these new words while writing them on the book. The researcher sees that each student has the method of memorizing the new words. If the teachers use the direct method, the students will be sure to memorize the words.

What is the main problem you face in class when the teacher uses the direct method of teaching?

The answers show that the main problem faced by students in the class is a weakness in the hearing of some students and reached $27 \%$, and half of them consider that the lack of vocabulary is the main problem, and $17 \%$ of students think it is weak speech, $6 \%$ of students think it Due to non-habituation. In view of the analysis of this question, the researcher noted that all students face the problem in applying teachers to the direct method.

\section{Discussion and Analysis}

Based on the analysis of the questionnaire, we have identified the types of problems and obstacles encountered in the course of the Arabic language in general and the direct method especially among the teachers and students at the Tongxin Arabic language college. In this regard, the researcher will present the findings through the presentation and analysis of questionnaires. We can summarize that the direct method faces practical problems in the Tongxin Arabic Language College as follows:

1- Most of the problems and difficulties of Arabic language education in the Tongxin Arabic Language College are lack of capable educators and teachers with experience and experience in the art of teaching Arabic to non-native speakers. Because $64 \%$ of teachers have more than five years of experience in education, but most of them do not care about their individual development. $56 \%$ of teachers do not participate in or never participate in training courses.

2- $70 \%$ of the teachers use the traditional method of teaching the Arabic language, which depends mainly on the maintenance of grammar, not on the practice of daily language, and depends on the way the Arabic words translated characters into Chinese. This indicates that there is no appropriate Arab environment inside and outside the college. This may be a major reason why students do not speak Arabic very well and that they are very ashamed when using Arabic in the classroom or outside.

3- The inconsistency of the distribution of the number of shares among teachers, the researchers believe that some teachers have many quotas, and they do not have sufficient times to study the modern method of high level of education. 
4- Most students have difficulty learning Arabic and the most important problems are hearing and speech impairment. Because $75 \%$ of students do not want the professor to use the direct method length of the lesson, this tells us that they are weak in listening and speaking and relying on the mother language. As well as $65 \%$ of the teachers see that their students are not excellent in the skill of speech, this means that the ability of students in the skill of speech need to upgrade and development is an urgent need for them.

5- Lack of strong desire of students in the study, which makes them have difficulty in speaking Arabic, and this is why the head leads to believe that the Arabic language is more difficult than other subjects. And the shortage of participation of students in associations or linguistic activities.

\section{Conclusion}

This research has reached the end door after the researchers had made the utmost efforts in reviewing the books related to teaching methods of the Arabic language, especially the direct method and collecting information and analyzing it.

After analysis, the researchers presented practical problems for the direct method in the Tongxin Arabic Language College and some treatment methods, as well as some valuable suggestions addressed to the teachers, the learners and the college administration as well.

Therefore, the researchers will benefit greatly from this research, either in the field of the concept of the direct method and its characteristics or in the field of teaching methods in this college. Finally, the researchers hope that modest work will create a new path in this regard, and benefit others who practice Arabic language teaching or wish to study the direct method completely and comprehensively.

\section{Ssuggestions and Recommendations}

Based on the results mentioned above, the researchers mention some of the following suggestions and recommendations:

1- For the Department of Education: Working on the development of teachers' training curricula: Through the presentation and analysis of the questionnaire, it was clear that all of them recognized the urgent need for training courses to teach Arabic as a second language to improve their performance. These teachers cannot do their job in language and science at best unless they have received a sufficient share of educational and cultural preparation, especially in the art of teaching Arabic.

\section{2- For the Tongxin Arabic Language College:}

1)-the Dean of the Department of Education should consider to reduce their heavy loads so that they can devote their efforts to the educational process and scientific research.

2)-The College should follow the best method of raising the level of performance among teachers of the Arabic language by sending them to training courses or scientific seminars or workshops to teach Arabic language to non-native speakers, especially in teaching methods and methods. As well as their training on teaching methods in general and the direct method in particular.

3)- It is necessary to provide the creation of a room for teaching aids, in which audiovisual aids are collected from tapes, films, television screens, recording devices, web boards and other modern teaching aids for teachers to use in their education.

4) The College should encourage teachers to carry out research studies that are directly related and applied in the Tongxin College of Arabic Language. They should avoid using inappropriate teaching methods.

\section{3- For teachers:}

1) - to practice the direct method of their students in the primary stage and that students return this method from the beginning of the study to develop the idea of language. And avoid from traditional methods inherited.

2)- to understand the characteristics of the direct method is a good understanding, namely that the teacher uses the Arabic language only in the process of teaching without other languages, and much of the dialogue and conversation in Arabic between the teacher and students, so that the teacher role model for students should initiate the conversation in Arabic. 


\section{4- For students:}

1)- to address the psychological problems facing them such as laziness and lack of diligence and desire and inclination to study all individuals can deal with them himself.

2) - to train themselves to practice the skill of listening to the Arabic audio materials always to enable him to acquire this skill, we have been able to master the skill of speech to the degree of speech that approach the words of the owners of the language themselves.

3)- To initiate the expulsion of oral questions in Arabic on the subject of the study and to participate in the language activities in which the college is held or by the teacher in the classroom or outside.

\section{References}

[1] Abu Al - Higa, Fouad Hassan Hussein. (2007). Techniques and methods of teaching Arabic language and preparing daily lessons. Jordan: Curriculum House.

[2] Al - Jaafra, Abdul Salam Yusuf. (2011). Arabic language curricula and methods of teaching between theory and practice. Jordan: Arab Community Library.

[3] Al Zu'bi, Bashir Rashid. (2009). Development of absorption skills among Arabic-speaker students, Jordan: Dar Al-Badiya and Dar Al-Mustaqbal.

[4] Al - Khatib, Mohammed Ibrahim. (2009). Arabic language curricula and methods of teaching in basic education. Jordan: Al-Waraq Foundation.

[5] Ali Majawar, Mohamed Salah Eddin. (2000). Teaching Arabic in the secondary stage.

[6] Abdullah Ali Mustafa. (2002). Arabic Language Skills. House of the march. House of the march. Amman. Jordan.

[7] Abdullah bin Joussouh. (1998). Teaching Arabic in four secondary schools in the state of Malacca A supplementary study to obtain a master's degree in education. Malaysia: International Islamic University.

[8] Abd El Fattah Hassan El Beja. (1999). The origins of teaching Arabic between theory and practice. Dar Al Fikr. Amman. Jordan.

[9] Ashour, QasimRatib \& Al Hawamdeh, Mohammed Foad. (2010). Methods of teaching Arabic language between theory and practice. Jordan: House of the march.

[10] Bao, E Ma. (2011). Muslims in Ningxia. China: People's Publishing House, Ningxia.

[11] Ibrahim, Mohamed Abdel Rahman. (2016). Students' Guide to Scientific Research Language. Malaysia: International Islamic University of Malaysia.

[12] Iti, Hassan bin AbdulWahab. (2006). Curriculum in Arabic Language at the Islamic College in Jala (Evaluation Study). Malaysia: International Islamic University.

[13] Mohammed bin Ibrahim al-Khatib. (2003). Methods of teaching Arabic. Library of repentance. Riyadh. Saudi.

[14] Mohammed Ibrahim Al-Khatib. (2009). Arabic language curricula and methods of teaching in basic education. Al - Waraq Foundation. Amman. JordanZakaria, Gamal Abdel Nasser. (2016). The introduction of Teaching Arabic to non- native Speakers: Methods and Concepts. Malaysia: International Islamic University of Malaysia.

[15] Madkour, Ali Ahmed. (2009). TeachingArabic arts: Theory and Practice. Jordan: House of the march.

[16] Nabil Abdel Hadi. Abdul Aziz Abu Hashish. Khaled Al-Karim Basendi. (2005). Language and Thinking Skills. Library of Repentance. Riyadh. Saudi.

[17] Yousef Al - Smaili. (2002). Arabic language and methods of teaching theory and practice. Modern Library. Beirut. Lebanon.

[18] Walid Ahmed Jaber. (2002). Teaching Arabic concepts and practical applications. Dar Al Fikr. Amman. Jordan..

[19] Zakaria, Zarimabinti Mohamed. (2005). Malaysian students' written expression in secondary schools in Selangor "Analytical descriptive study". Malaysia: Islamic International University. 